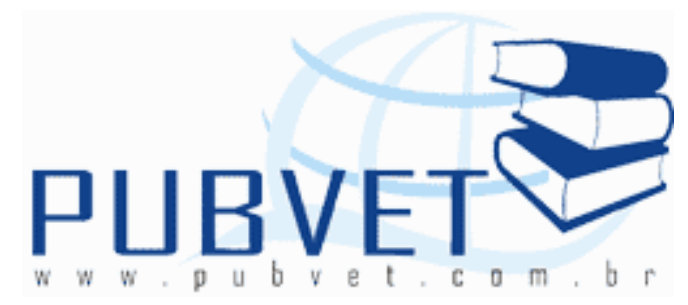

PUBVET, Publicações em Medicina Veterinária e Zootecnia.

\title{
Condimentos e especiarias empregados no processamento de alimentos: considerações a respeito de seu controle físico-químico
}

Kênia de Fátima Carrijo ${ }^{1 *}$; Carla Inês Soares Praxedes²; Francesca Silva Dias Nobre $^{3}$; Beatriz da Silva Frasão ${ }^{4}$ Marjorie Toledo Duarte ${ }^{5}$; Fernanda Lima Cunha ${ }^{6}$

${ }^{1 *}$ Docente da Faculdade de Medicina Veterinária, Universidade Federal de Uberlândia (UFU). Endereço: Rua Ceará, s/n, Bloco 2D, sala 29, CEP: 38.402018, Uberlândia-MG, Brasil. Telefone: (34) 3218-2231. E-mail: keniacarrijo@famev.ufu.br.

${ }^{2}$ Centro Federal de Educação Tecnológica Celso Suckow da Fonseca - CEFET Núcleo Avançado de Valença, Valença-RJ, Brasil.

${ }^{3}$ Docente da Faculdade de Medicina Veterinária, Universidade Federal do Vale do São Francisco (UNIVASF), Petrolina-PE, Brasil.

${ }^{4}$ Discente da Faculdade de Medicina Veterinária, Universidade Federal de Uberlândia (UFU), Uberlândia-MG, Brasil.

${ }^{5}$ Docente da Faculdade de Medicina Veterinária, Universidade Severino Sombra (USS), Vassouras-RJ, Brasil.

${ }^{6}$ Doutoranda do Programa de Pós Graduação em Higiene Veterinária e Processamento Tecnológico de Produtos de Origem Animal. Faculdade de Veterinária. Universidade Federal Fluminense (UFF). Niterói-RJ, Brasil. 
CARRIJO, K.F. et al. Condimentos e especiarias empregados no processamento de alimentos: considerações a respeito de seu controle físico-químico. PUBVET, Londrina, V. 6, N. 26, Ed. 213, Art. 1419, 2012.

\title{
Resumo
}

Condimentos e especiarias são empregados no processamento tecnológico de alimentos com o objetivo de conferir sabor, aumentar a vida comercial dos produtos, em função de sua ação antioxidante, além de agregar valor aos alimentos, permitindo sua diversificação no mercado. Além da importância tecnológica, estes produtos trazem benefícios à saúde de quem os consome, quando usados adequadamente, estimulando a secreção gástrica e aumentando o tônus dos órgãos digestivos. No entanto, podem veicular microrganismos e matérias estranhas, causando riscos à saúde do consumidor. Para que sua qualidade e propriedades desejáveis sejam mantidas, torna-se necessário realizar um rigoroso controle de qualidade, garantindo a inocuidade dos mesmos, através de Boas práticas agrícolas, boas práticas de fabricação, controle macroscópico e microscópico, análises microbiológicas e físicoquímicas. Os métodos físico-químicos oficiais são um instrumento para a fiscalização do uso destes componentes empregados pela indústria alimentícia. Desta forma, esta revisão de literatura reúne informações e conhecimentos a respeito dos condimentos e especiarias e dos principais métodos de controle físico-químico destinados a garantir sua qualidade.

Palavras-chave: condimentos, especiarias, controle físico-químico, qualidade.

\section{Condiments and spices employees in the food processing: considerations regarding its physical and chemical control}

\begin{abstract}
Condiments and spices are used in food processing technology with the purpose of flavor, increase the commercial shelf-life of products, due to its antioxidant action, besides adding value to food, allowing diversification in the market. Besides the benefit of technology, these products provide health benefits for those who consume when used appropriately, stimulating gastric secretion and increasing the tonus of the digestive organs. However, can carry microorganisms and foreign matter, causing health risks to the consumer. For
\end{abstract}


CARRIJO, K.F. et al. Condimentos e especiarias empregados no processamento de alimentos: considerações a respeito de seu controle físico-químico. PUBVET, Londrina, V. 6, N. 26, Ed. 213, Art. 1419, 2012.

your quality and desirable properties are maintained, it becomes necessary to conduct a rigorous quality control, ensuring the safety of themselves through good agricultural practices, good manufacturing practices, control macroscopic and microscopic, microbiological and physical-chemical properties. The physico-chemical methods are an official tool for monitoring the use of these components used by the food industry. Thus, this literature review gathers information and knowledge about the condiments and spices and the main methods of physico-chemical control to ensure its quality.

Keywords: Spices, control physical and chemical, quality.

\section{INTRODUÇÃO}

O termo condimento é popularmente empregado, de modo genérico, para se designar os ingredientes aromáticos, de sabor forte ou picante, adicionados com o objetivo de melhorar ou modificar o sabor dos produtos processados, possibilitando a diferenciação e diversificação de produtos, através de um paladar único. Especiarias são condimentos simples, sendo empregados apenas produtos vegetais. Já os condimentos preparados referem-se a uma mistura de especiarias com outros ingredientes alimentícios. Ambos possuem a propriedade de modificar o sabor dos alimentos.

Além de contribuírem com o sabor, muitas das especiarias utilizadas na condimentação podem apresentar efeito conservante e propriedades antioxidantes, características bastante interessantes no processamento tecnológico de produtos alimentícios, sobretudo carnes. Por outro lado, muitas das especiarias podem ser responsáveis pela redução da vida útil de tais produtos, uma vez que se não produzidas e armazenadas adequadamente, podem conter altas cargas microbianas. Muitas empresas fornecedoras de especiarias têm esterilizado seus produtos a serem destinados à indústria processadora de carnes e para uso doméstico, numa tentativa de minimizar prejuízos e riscos para a saúde coletiva. 
CARRIJO, K.F. et al. Condimentos e especiarias empregados no processamento de alimentos: considerações a respeito de seu controle físico-químico. PUBVET, Londrina, V. 6, N. 26, Ed. 213, Art. 1419, 2012.

Além do risco sob o aspecto microbiológico, especiarias e condimentos podem ser adulterados, pela adição de material de outras plantas ou especiarias mais baratas, adição de amido e incorporação de materiais estranhos. Além de lesar economicamente o consumidor, as fraudes representam um sério perigo à saúde de quem as ingere, em função do risco físico que a presença de determinados materiais pode trazer.

O presente trabalho teve como objetivo apresentar a importância e os riscos da utilização de condimentos e especiarias para a saúde coletiva, através do entendimento dos métodos físico-químicos utilizados para o controle de qualidade destes produtos.

\section{REVISÃO DE LITERATURA}

\subsection{DEFINIÇÃO}

A definição de "condimento" segundo o Regulamento da Inspeção Industrial e Sanitária de Produtos de Origem Animal - RIISPOA (BRASIL, 2008) é "o produto contendo substâncias aromáticas, sápidas, com ou sem valor alimentício, empregado com o fim de temperar alimentos, dando-lhe melhor aroma e sabor". Segundo este regulamento, 28 condimentos listados tem seu uso permitido, sendo que alguns podem ainda ser empregados como corantes. Outros condimentos podem ter seu uso permitido desde que aprovados pelos órgãos regulamentadores.

A Resolução n 12 da Comissão Nacional de Normas e Padrões para Alimentos (CNNPA), classificava condimentos e temperos em três classes: glutamato monossódico, sais sódicos dos ácidos ribonucléicos (sal e açúcar) e especiarias ou condimento vegetal (BRASIL, 1978). No entanto, o glutamato monossódico através do Regulamento Técnico que aprova o uso de Aditivos com a função de realçadores de sabor (BRASIL, 2001), passou a ser classificado como aditivo alimentar com tal função. Gerhardt (1975) considera 
CARRIJO, K.F. et al. Condimentos e especiarias empregados no processamento de alimentos: considerações a respeito de seu controle físico-químico. PUBVET, Londrina, V. 6, N. 26, Ed. 213, Art. 1419, 2012.

o sal e o açúcar como condimentos saporizantes, quando utilizados em baixas concentrações e com a função apenas de dar sabor aos alimentos.

Germano e Germano (1998) definem especiaria segundo o conceito utilizado no Primeiro Congresso Internacional para Repressão da Fraude, em Genebra em 1908. Ficou assim definido: "designam-se com o nome de especiarias as substâncias vegetais de origem indígena ou exótica, aromáticas ou de sabor forte, picante, utilizadas para realçar o gosto dos alimentos ou adicionar-lhes os princípios estimulantes nelas contidas". Neste sentido, o termo especiaria aplica-se a produtos naturais de origem vegetal, ou à sua mistura (como é o caso do curry, que é o resultado de uma mistura de especiarias simples, sem a adição de outros ingredientes), estabilizados, inteiros, fragmentados ou em pó, sem a adição de matérias de outra natureza.

Já o Regulamento Técnico para Especiarias, temperos e molhos (BRASIL, 2005b) define especiarias como sendo "produtos constituídos de partes (raízes, rizomas, bulbos, cascas, folhas, flores, frutos, sementes, talos) de uma ou mais espécies vegetais, tradicionalmente utilizadas para agregar sabor ou aroma aos alimentos e bebidas". Define ainda temperos como sendo "produtos obtidos da mistura de especiarias e de outros ingredientes, fermentados ou não, empregados para agregar sabor ou aroma aos alimentos e bebidas" e molhos como sendo "produtos em forma líquida, pastosa, emulsão ou suspensão à base de especiaria(s) e ou tempero(s) e ou outro(s) ingredientes(s), fermentados ou não, utilizados para preparar ou agregar sabor e aroma aos alimentos e bebidas".

Apesar de não haver uma definição que diferencie claramente o termo condimento de especiaria, levando-se em consideração a Resolução $n^{\circ} 12$ da CNNPA (BRASIL 1978), o termo condimento possui sentido mais amplo, sendo muitas vezes empregado na literatura, como sinônimo de tempero. O termo especiaria se restringe ao condimento vegetal simples, sem adição de outros ingredientes, enquanto que condimento pode se referir tanto ao condimento vegetal simples (ou especiaria) ou condimento preparado (especiarias adicionadas de óleos comestíveis, ovos, sal, açúcar, limão, vinagre e de outras 
CARRIJO, K.F. et al. Condimentos e especiarias empregados no processamento de alimentos: considerações a respeito de seu controle físico-químico. PUBVET, Londrina, V. 6, N. 26, Ed. 213, Art. 1419, 2012.

substâncias alimentícias aprovadas). Dessa maneira, tanto especiaria (condimento vegetal simples) quanto condimento (especiaria + outros ingredientes) têm a propriedade de agregar sabor e aroma ao alimento.

A seguir serão abordados aspectos históricos relativos ao uso de condimentos e especiarias, até os dias atuais.

\subsection{HISTÓRICO DO USO DE CONDIMENTOS E ESPECIARIAS}

Especiarias e ervas tem sido usadas para uma grande variedade de funções desde os tempos pré-históricos, sendo a mais comum, a conservação de carnes. Nos tempos antigos, quando a preservação dos alimentos era inadequada, especiarias eram usadas para mascarar o sabor e o odor em produtos alimentícios, sobretudo carnes em início de decomposição. Algumas foram empregadas para embalsamar mortos no antigo Egito; com misturas de açafrão, alho, alho-poró, cardamomo, cássia, coentro, erva-doce, gergelim, mostarda, papoula, pimenta, tomilho (BEDIN et al., 1999; PRZYBYLA, 1986). Além das funções de temperar e conservar, as especiarias eram largamente utilizadas para fins medicinais e ainda como perfumes, cosméticos e afrodisíacos, segundo os escritos de gregos antigos, Romanos e Chineses (PARRY, 1953).

Nos tempos antigos, especiarias eram tão valorizadas que eram utilizadas como moeda e por muitos anos, foram tão caras que elas eram disponíveis somente para famílias muito ricas (McKEE, 1995).

As especiarias passaram a ser utilizadas no Ocidente, vindas nas embarcações durante o Descobrimento, época em que eram comercializadas a preços bastante elevados (CHESCA et al., 2004). Pedro Álvares Cabral em 1500, antes de chegar às Índias, descobriu o Brasil, onde os portugueses procuraram por fontes de lucro imediato, e não encontraram. Dessa forma, as especiarias tiveram papel importante em expansão marítima portuguesa e, consequentemente, na descoberta do Brasil (ALMEIDA, 2006). 
CARRIJO, K.F. et al. Condimentos e especiarias empregados no processamento de alimentos: considerações a respeito de seu controle físico-químico. PUBVET, Londrina, V. 6, N. 26, Ed. 213, Art. 1419, 2012.

Em função dessa maior disseminação das especiarias, houve maior conhecimento de suas propriedades e só aos poucos se viu que tornavam também as receitas mais saborosas, além de adicionar uma característica exclusiva ao alimento. Usadas com habilidade, transformam a cozinha em arte, fornecendo cor e sabor picante ou exótico. Ao lado de sua utilização em culinária, as especiarias são largamente empregadas, também, como aromatizantes de licores, destacando entre eles: absinto, Anisette (anis), Bénédictine (composto por 27 ervas), Kümmel (cominho e erva-doce), Pernod (anis) e o Ouzo (anis) (GERMANO e GERMANO, 1998).

Além das propriedades apontadas, as especiarias desde que utilizadas de maneira adequada, facilitam a digestão humana, promovendo maior salivação e secreção mais abundante das glândulas gástricas, além de aumentar o peristaltismo intestinal, proporcionando a degradação do alimento até a fase final (CHESCA et al, 2004). No entanto, em quantidades excessivas podem acarretar distúrbios gastrointestinais, sendo contra-indicadas nas nefropatias (GERMANO e GEMANO, 1998).

Segundo Gerhardt (1975) além de proporcionar odores e sabores característicos aos alimentos, as especiarias possuem atividade antioxidante em relação às gorduras. Estas retiram da gordura o oxigênio necessário à formação de radicais, desenvolvendo-se assim a atividade antioxidante. Este autor relata ainda, que muitas especiarias opõem-se aos processos autoxidativos das gorduras, fixando traços de metais, agentes catalisadores da decomposição. Madhavi et al. (1996) citam que o alecrim, orégano, sálvia, cravo-da-índia e pimenta da Jamaica são alguns dos condimentos com significativas propriedades antioxidantes em produtos alimentícios, sendo que os compostos fenólicos, ativos nos condimentos, funcionam como antioxidantes primários.

Gehardt (1975) ainda atribui às especiarias uma verdadeira ação emulsionante quando se produz um processo de embebição ao contato com a água. A fixação da água fica na dependência não somente do tipo da especiaria, mas também da proporção das partículas, de seu número e da 
CARRIJO, K.F. et al. Condimentos e especiarias empregados no processamento de alimentos: considerações a respeito de seu controle físico-químico. PUBVET, Londrina, V. 6, N. 26, Ed. 213, Art. 1419, 2012.

temperatura atingida. Será tanto maior a capacidade de retenção de água quanto menores forem as partículas e mais elevada a temperatura.

Às especiarias, é atribuído o efeito antimicrobiano, em função de seus óleos essenciais, que são compostos voláteis, capazes de inibir o crescimento de uma variedade de microrganismos (BEDIN et al., 1999). Dentre os condimentos que possuem propriedades antimicrobianas, o alho é um dos que apresenta melhor potencial, pois além de ser um condimento normalmente utilizado no preparo de alimentos, possui um antimicrobiano natural, a alicina e diversas outras substâncias implicadas em diferentes controles microbianos de interesse. $O$ alho inibiu o crescimento in vitro de determinados microrganismos, como Bacillus cereus, Escherichia coli e Staphylococcus aureus (OLIVEIRA et al., 2003).

As especiarias podem ser utilizadas na forma de extratos, como óleo resina (extrato oleoso, em que contêm todas as substâncias que são solúveis no solvente utilizado), na forma de óleo essencial contendo os compostos que dão a característica à especiaria (compostos de aroma e sabor) ou na forma de planta natural ou seca (ARIMA e NETO, 1995).

Muitas especiarias crescem espontaneamente nos países tropicais, mas atualmente, a maior parte é produzida em escala industrial com a finalidade de exportação. A classificação destas em grupos não é fácil, podendo ser feita em função das suas propriedades sensoriais, em função da parte da planta que é utilizada (EGAN et al., 1987; ICMSF, 1985), com base nas características botânicas da planta de que provêm, ou ainda, numa classificação mista (HEATH, 1982).

A seguir serão apresentadas três classificações que as especiarias recebem, segundo os autores supracitados. 


\subsection{CLASSIFICAÇÃO DAS ESPECIARIAS}

\subsubsection{Classificação de acordo com a parte da planta de que procedem:}

- Rizomas e raízes; gengibre, cúrcuma.

- Bulbos: alho, cebola;

- Casca: canela

- Folhas; louro, manjerona, menta, sálvia, tomilho, orégano;

- Flores: açafrão, cravo, alcaparra;

- Frutos e sementes: pimenta, pimentão, cominho, mostarda, nozmoscada, pimenta da Jamaica, cardamomo, coentro, zimbre (genebra), baunilha, anis, aipo, aneto, erva-doce.

\subsubsection{Classificação de acordo com a família botânica:}

- Família das Zingiberáceas: gengibre, canela, baunilha, pimenta do reino;

- Família das Umbelíferas: anis, aneto, aipo, cominho, coentro.

- Família das Labiadas: sálvia, tomilho, manjerona, orégano, menta.

- Família das Iridáceas: açafrão;

- Família das Solanáceas: pimentão (páprica) e outros tipos de pimenta.

- Família das Liliáceas: alho, cebola;

- Família das Lauráceas: canela.

\subsubsection{Classificação de acordo com a sua ação:}

- Quentes: pimenta, mostarda, gengibre;

- Suaves: pimenta doce (páprica), coentro, louro;

- Aliáceos: alho, cebola, cebolinha.

A seguir serão apresentadas as principais especiarias e condimentos utilizados na indústria de alimentos, segundo o RIISPOA (BRASIL, 2008) e o Regulamento Técnico para Especiarias, temperos e molhos (BRASIL, 2005a). 
CARRIJO, K.F. et al. Condimentos e especiarias empregados no processamento de alimentos: considerações a respeito de seu controle físico-químico. PUBVET, Londrina, V. 6, N. 26, Ed. 213, Art. 1419, 2012.

\subsection{PRINCIPAIS ESPECIARIAS E CONDIMENTOS UTILIZADOS NA INDÚSTRIA DE ALIMENTOS}

O RIISPOA (BRASIL, 2008) em seu artigo 787, permite o emprego de 28 corantes e condimentos em produtos de origem animal, permitindo ainda 0 emprego de outros, desde que aprovados pela Divisão de Produtos de Origem Animal (DIPOA). Estes estão listados a seguir:

1 - açafrão (Croccus sativus, L);

2 - aipo (Apium graveolens e Celeri graveolens);

3 - alho (Allium sativum);

4 - aneto (Anethum graveolens);

5 - aniz (Pimpinela anizum, L);

6 - baunilha (Vanilia planifolia, Andrews);

7 - canela (Cinnamonun ceylanicum, Breure);

8 - cardamomo (Elleteria cardamomum);

9 - cebola (Allium cepa);

10 - cenoura (Dancus carota);

11 - coentro (Coriandrum sativum, L);

12 - cominho ( Cuminum cyminum);

13 - cravo da índia (Caryophylus aromaticus, L.);

14 - curcuma (Curcuma longa, L.);

15 - gengibre (Zinziber officinalis, Roscoe);

16 - louro (Laurus nobilis, L.);

17 - macis ( envoltório da Myristica Fragans, Maute);

18 - maiorana (Anethum graveolens);

19 - manjerona (Origanum majorana, L.);

20 - mento (M. viridis, M. rotundifolia e M. piperita L.),

21 - mostarda:

negra (Brassiva nigra, Koen);

parda (Brassiva juncea, Hocker);

branca (Sinapis Alba, L.) e misturas; 
CARRIJO, K.F. et al. Condimentos e especiarias empregados no processamento de alimentos: considerações a respeito de seu controle físico-químico. PUBVET, Londrina, V. 6, N. 26, Ed. 213, Art. 1419, 2012.

22 - noz-moscada (Myristica fragans, Maute) desprovida completamente de envoltório;

23 - pimenta:

negra (Piper nigrum, L.);

branca (mesmo fruto, porém descorticado);

vermelha ou pimenta de Caiena (Capsicum baccatum. L.);

malagueta (Capsicum pendulum, velloso);

24 - pimentão (Paprika) (Capsicum anuum L.);

25 - pimento ou pimenta da Jamaica ou pimenta inglesa (Pimenta officinalis, Linds);

26 - salvia (Salvia officinalis, L.);

27 - tomilho (Thymis vulgaris, L.);

28 - Urucum (Bixa orellana).

Já as Normas Técnicas especiais para alimentos e bebidas (BRASIL, 1978), estabelece as características gerais, sensoriais e físico-químicas de 19 especiarias ou condimentos vegetais, determinando ainda tais características referentes aos condimentos preparados, os quais são: catchup ou ketchup, maionese, mostarda de mesa ou mostarda preparada, molho inglês Worcestershire, molho Shoyu ou Molho Japonês. Os valores obtidos em análises físico-químicas de condimentos devem ser comparados com os valores de referência contidos nesta norma, para verificar se tais produtos analisados se encontram dentro dos padrões.

Já o Regulamento Técnico para especiarias, temperos e molhos (BRASIL, 2005b), estabeleceu uma lista de especiarias de uso aprovado (quadro 1), e atenta para o fato de que, uma espécie vegetal ou uma parte sua ou ingrediente que não são usados tradicionalmente como alimento poderão ser autorizados, desde que seja comprovada a segurança de uso do produto. 
CARRIJO, K.F. et al. Condimentos e especiarias empregados no processamento de alimentos: considerações a respeito de seu controle físico-químico. PUBVET, Londrina, V. 6, N. 26, Ed. 213, Art. 1419, 2012.

Quadro 1: Lista de Especiarias aprovadas para uso segundo o Regulamento Técnico para Especiarias, temperos e molhos (BRASIL, 2005b)

\begin{tabular}{|l|l|}
\hline NOME COMUM / NOME CIENTÍFICO & $\begin{array}{l}\text { PARTE DO VEGETAL } \\
\text { UTILIZADA }\end{array}$ \\
\hline Açafrão / Crocus sativus L. & estigmas florais \\
\hline Aipo marrom e verde / Apium graveolens L. & $\begin{array}{l}\text { talos, folhas } \\
\text { sementes }\end{array}$ \\
\hline Alcaçuz / Glycyrrhiza glabra L. & raízes \\
\hline Alcaparra / Capparis spinosa L. & botões florais \\
\hline Alecrim / Rosmarinus officinalis L. & folhas e talos \\
\hline Alho / Allium sativum L. & bulbos \\
\hline Alho porro / Allium porrum L. & folhas e talos \\
\hline Anis estrelado / Illicium verum Hook. & frutos \\
\hline Baunilha / Vanilla planifolia Jacks. & frutos \\
\hline Canela-da-china / Cinnamomum cassia Ness ex Blume & cascas \\
\hline Canela-do-ceilão / Cinnamomum zeylanicum Ness & cascas \\
\hline Cardamono / Elettaria cardamomum L. & sementes \\
\hline Cebola / Allium cepa L. & bulbos \\
\hline Cebolinha verde / Allium schoenoprasum L. & folhas e talos \\
\hline Cerofólio / Anthriscus cerofolium (L.) Hoffm. & folhas e frutos \\
\hline Coentro / Coriandrum sativum L. & talos, folhas e frutos \\
\hline Cominho / Cuminun cyminum L. & frutos \\
\hline Cravo-da-índia / Caryophyllus aromaticus L. ou Eugenia & botões florais \\
\hline Currcumallata Thumb / Curcuma longa L. e Curcuma domestica & rizomas \\
\hline Valenton & folhas \\
\hline Endro ou aneto ou dill / Anethum graveolens L. & frutos, folhas e talos \\
\hline
\end{tabular}


CARRIJO, K.F. et al. Condimentos e especiarias empregados no processamento de alimentos: considerações a respeito de seu controle físico-químico. PUBVET, Londrina, V. 6, N. 26, Ed. 213, Art. 1419, 2012.

\begin{tabular}{|l|l|}
\hline Erva-doce ou anis ou anis doce / Pimpinella anisum L. & frutos \\
\hline Estragão / Artemisia dracunculus L. & folhas e talos \\
\hline Feno-grego / Trigonella foenum-graecum L. & sementes \\
\hline Funcho / Foeniculum vulgare Mill. & folhas e talos \\
\hline Gengibre / Zingiber officinale Roscoe & rizomas \\
\hline Gergelim / Sesamum indicum L. & sementes \\
\hline Hortelã ou hortelã-pimenta / Mentha piperita L. & folhas e talos \\
\hline Kümmel ou alcaravia / Carum carvi L. & sementes \\
\hline Louro / Laurus nobilis L. & folhas \\
\hline $\begin{array}{l}\text { Manjericão ou alfavaca ou basílico / Ocimum basilicum } \\
\text { L. }\end{array}$ & folhas e talos \\
\hline $\begin{array}{l}\text { Manjerona / Majorana hortensis Moench. ou Origanum } \\
\text { majorana L. }\end{array}$ & folhas e talos \\
\hline $\begin{array}{l}\text { Menta ou menta doce ou hortelã-doce / Mentha arvensis } \\
\text { L. }\end{array}$ & folhas e talos \\
\hline $\begin{array}{l}\text { Mostarda-branca / Sinapsis alba L. ou Brassica alba } \\
\text { Rabenth }\end{array}$ & sementes \\
\hline $\begin{array}{l}\text { Mostarda-preta / Brassica nigra (L.) Koch ou Sinapis } \\
\text { nigra L. }\end{array}$ & sementes \\
\hline $\begin{array}{l}\text { Mostarda amarela ou parda / Brassica hirta Moench. ou } \\
\text { Brassica juncea L. }\end{array}$ & fementes \\
\hline Noz-moscada ou macis / Myristica fragrans Houtt & sementes e arilos \\
\hline Orégano chileno / Origanum vulgare L. & folhas e talos \\
\hline Orégano mexicano / Lippia graveolens Kunth & sementes \\
\hline Papoula / Papaver somniferum L. & \\
\hline Pánica / Capsicum annuum L. & frutos \\
\hline
\end{tabular}


CARRIJO, K.F. et al. Condimentos e especiarias empregados no processamento de alimentos: considerações a respeito de seu controle físico-químico. PUBVET, Londrina, V. 6, N. 26, Ed. 213, Art. 1419, 2012.

\begin{tabular}{|l|l|}
\hline Pimenta-de-caiena / Capsicum baccatum L. & frutos \\
\hline $\begin{array}{l}\text { Pimenta vermelha ou pimenta-malagueta/ Capsicum } \\
\text { frutescens L. }\end{array}$ & frutos \\
\hline $\begin{array}{l}\text { Pimenta cumari / Capsicum praetermissum Heiser \& } \\
\text { Smith }\end{array}$ & frutos \\
\hline $\begin{array}{l}\text { Pimentão vermelho, pimentão verde, pimentão amarelo } \\
\text { e pimenta doce / Capsicum annum L. }\end{array}$ & \\
\hline $\begin{array}{l}\text { Pimenta-da-jamaica / Pimenta officinalis Lindl. oufrutos } \\
\text { Pimenta dioica (L.) Merr. }\end{array}$ & \\
\hline Pimenta rosa / Schinus terebinthifolius Raddi & frutos \\
\hline Raiz forte / Armoracia rusticana P. Gaertn & folhas e raízes \\
\hline Salsa / Petroselinum sativum Hoffm. ou Petroselinum & folhas e talos \\
crispum (Mill.) Nyman. & folhas \\
\hline Sálvia / Salvia officinalis L. & folhas e talos \\
\hline Segurelha / Satureja hortensis L. & folhas e talos \\
\hline Tomate/ Lycopersicum esculentum L. & sementes \\
\hline Tomilho / Thymus vulgaris L. & \\
\hline Urucum / Bixa orellana L. & \\
\hline Zimbro / Juniperus communis L. & \\
\hline
\end{tabular}

FONTE: BRASIL (2005b)

2.5 PROBLEMAS HIGIÊNICO-SANITÁRIOS E DE SAÚDE PÚBLICA RELACIONADOS COM O USO DE CONDIMENTOS E ESPECIARIAS

Apesar de amplamente utilizadas, as especiarias e condimentos apresentam algumas limitações quanto ao seu uso, principalmente com relação às contaminações e adulterações.

As especiarias podem ser contaminadas na origem, na estocagem, no transporte ou mesmo durante a manipulação, por esporos, fungos e leveduras, 
CARRIJO, K.F. et al. Condimentos e especiarias empregados no processamento de alimentos: considerações a respeito de seu controle físico-químico. PUBVET, Londrina, V. 6, N. 26, Ed. 213, Art. 1419, 2012.

os quais nas indústrias de alimentos podem causar sérios danos, notadamente nos produtos enlatados. Do mesmo modo, podem ser contaminadas por insetos (GERMANO e GERMANO, 1998).

Tanto as condições sanitárias das plantações quanto os cuidados na colheita, influem nos níveis de contaminação. As superfícies externas dos vegetais se contaminam a partir do solo, água, materiais fecais, ar, animais e manipuladores, de forma que os microrganismos presentes neles, se somam à microbiota natural daqueles (OLIVEIRA, 1992). Por outro lado, o armazenamento em galpões velhos, úmidos, mal ventilados, com paredes cobertas de bolor, propiciam a multiplicação das espécies contaminantes e/ou novas espécies a partir do ambiente (GERMANO e GERMANO, 1998).

Além de interferir na qualidade e vida útil dos alimentos onde esses ingredientes foram adicionados, são considerados importantes fontes de contaminação não só para alimentos processados, mas também para não processados, podendo ocasionar problemas de saúde para quem os ingere (FROEHLICH e GIOMBELLI, 2002).

Além de análises microbiológicas para avaliação de qualidade de condimentos e especiarias, deve-se recorrer a exames macroscópicos, microscópicos, físicos e químicos, para a comprovação de eventuais adulterações (GERHARDT, 1975).

Para a avaliação de matérias macroscópicas e microscópicas podem ser utilizadas a observação direta e/ou observação com auxilio de instrumentos ópticos, devendo ser utilizados os métodos de análise recomendados pela Association of Chemical Analytical Chemists International (AOAC), pela International Organization for Standarization (ISO), pelo Instituto Adolfo Lutz e pela Comissão do Codex Alimentarius e seus comitês específicos ou outros métodos validados segundo protocolos adotados por entidades internacionalmente reconhecidas (BRASIL, 1999).

Com relação às adulterações (fraudes) em condimentos e especiarias, Gehardt (1975) afirma que de maneira geral, estas são de natureza econômica e visam fraudar o produto de modo a vender um condimento de qualidade 
CARRIJO, K.F. et al. Condimentos e especiarias empregados no processamento de alimentos: considerações a respeito de seu controle físico-químico. PUBVET, Londrina, V. 6, N. 26, Ed. 213, Art. 1419, 2012.

inferior por outro de qualidade superior, ou fazer uso de substâncias estranhas, de modo adulterar o peso do produto final.

Segundo as Normas Técnicas Especiais para alimentos e bebidas (BRASIL, 1978), o condimento vegetal, além de ser constituído de especiarias genuínas e puras, estas devem estar limpas e sãs, devem corresponder às suas características botânicas normais e estarem isentas de elementos vegetais estranhos à espécie de partes da planta de origem, que não possuam as características de condimento vegetal. Já o condimento preparado, além de ser obtido de especiarias genuínas, todos os ingredientes empregados devem estar em perfeito estado de conservação, sendo permitida a adição de amido na quantidade máxima de $10 \%$, nos casos previstos.

Em condimentos vegetais, é importante a identificação da espécie e a verificação de adulteração. Pardi et al. (1996) e o Instituto Adolfo Lutz (BRASIL, 2005a) destacam que dentre as adulterações (fraudes) mais frequentes encontradas destacam-se: substituição de especiarias mais caras por mais baratas, adição de material de outras plantas, adição de partes da planta de origem que não possuem as qualidades essenciais do condimento, incorporação de materiais estranhos durante a colheita, adição de amido ou farinha de grãos de cereais e adição de elementos estranhos moídos, principalmente quando o condimento é apresentado sob a forma de pó. Estes elementos adulterantes podem ser identificados pelo exame microscópico e a sua interferência nas características químicas por parâmetros químicos de qualidade, conforme estabelecidos em regulamento técnico específico.

Através do Regulamento Técnico de Avaliação de Matérias Macroscópicas e Microscópicas prejudiciais à saúde humana em alimentos embalados (BRASIL, 2003), estabeleceu-se que produtos que apresentem qualquer matéria prejudicial à saúde humana, identificada macroscopicamente, torna o produto e/ou lote impróprio para o consumo e dispensa a determinação microscópica. Entre as matérias prejudiciais à saúde humana, incluem-se insetos em qualquer fase de desenvolvimento, vivos ou mortos, inteiros ou em partes, reconhecidos como vetores mecânicos; outros animais vivos ou 
CARRIJO, K.F. et al. Condimentos e especiarias empregados no processamento de alimentos: considerações a respeito de seu controle físico-químico. PUBVET, Londrina, V. 6, N. 26, Ed. 213, Art. 1419, 2012.

mortos, inteiros ou em partes, reconhecidos como vetores mecânicos; parasitos; excrementos de insetos e/ou de outros animais; objetos rígidos, pontiagudos e/ou cortantes, que podem causar lesões no consumidor.

\subsection{MÉTODOS FÍSICO-QUÍMICOS DE ANÁLISES DE CONDIMENTOS}

Os componentes que caracterizam os sabores existentes nas especiarias são constituídos de uma composição de alcoóis, ésteres, aldeídos, terpenos, fenóis, ácidos orgânicos e muitos outros elementos que não foram totalmente identificados (SOUZA et al., 2005). Além destes componentes, as especiarias contêm também componentes da planta, tais como proteínas, carboidratos, óleos fixos, taninos, pigmentos, elementos minerais, etc. (PARDI et al., 1996). A perda de qualidade das especiarias traduz-se por diminuição das propriedades sensoriais, tais como cor, odor e sabor (GERMANO e GERMANO, 1998).

A seguir serão abordados os principais métodos de análise de condimentos simples (especiarias) e condimentos preparados utilizados no controle de qualidade destes.

\subsubsection{Métodos de Análise de Condimentos Simples (Especiarias)}

$\mathrm{Na}$ análise química de condimentos simples (especiarias) geralmente determina-se segundo o Instituto Adolfo Lutz (BRASIL, 2005a), substâncias voláteis, cinzas, cinzas insolúveis em ácido clorídrico a 10\%, extrato etéreo, extrato alcoólico e teor de óleos essenciais.

A seguir serão apresentadas as análises físico-químicas utilizadas para determinar a qualidade das especiarias, segundo o Instituto Adolfo Lutz (BRASIL, 2005a). 
CARRIJO, K.F. et al. Condimentos e especiarias empregados no processamento de alimentos: considerações a respeito de seu controle físico-químico. PUBVET, Londrina, V. 6, N. 26, Ed. 213, Art. 1419, 2012.

2.6.1.1 Determinação de Substâncias Voláteis - Secagem em estufa a $105^{\circ} \mathrm{C}$ (BRASIL, 2005a)

Esta prova tem seu princípio fundamentado na perda de substâncias voláteis após o aquecimento direto da amostra a $105^{\circ} \mathrm{C}$.

PROCEDIMENTO: Pesa-se de 2 a 10 gramas da amostra em cápsula de porcelana ou de metal, previamente tarada. Esta deverá ser aquecida durante 3 horas em estufa a $105^{\circ} \mathrm{C}$. Resfriar em dessecador até a temperatura ambiente. Pesar. Repetir a operação de aquecimento e resfriamento até obter peso constante.

CÁLCULO: $100 \times \mathrm{N}=$ substâncias voláteis a $105^{\circ} \mathrm{C}$ por cento $\mathrm{m} / \mathrm{m}$

$P$

$\mathrm{N}=\mathrm{n}^{\circ}$ de gramas substâncias voláteis (perda de massa em gramas)

$\mathrm{P}=\mathrm{n}^{\circ}$ de gramas da amostra

2.6.1.2 Resíduo por incineração - Cinzas (BRASIL, 2005a)

Esta prova tem seu princípio fundamentado na perda de peso que ocorre na amostra quando esta é incinerada a uma temperatura próxima a 550$570^{\circ} \mathrm{C}$. Permite avaliar a constituição da especiaria em relação às substâncias inorgânicas.

PROCEDIMENTO: Pesar 5 a 10 gramas da amostra em uma cápsula, previamente aquecida em mufla a $550^{\circ} \mathrm{C}$, resfriada em dessecador até a temperatura ambiente e pesada. Caso a amostra seja líquida, evapore em banho-maria. Secar em chapa elétrica, carbonizar em temperatura baixa e incinerar em mufla a $550^{\circ} \mathrm{C}$, até a eliminação completa do carvão. Em caso de borbulhamento, deve-se adicionar inicialmente algumas gotas de óleo vegetal para auxiliar o processo de carbonização. As cinzas devem ficar brancas ou ligeiramente acinzentadas. Caso isto não ocorra, deve-se esfriar a amostra em dessecador e adicionar $0,5 \mathrm{~mL}$ de água, secar e incinerar novamente. Resfriar 
CARRIJO, K.F. et al. Condimentos e especiarias empregados no processamento de alimentos: considerações a respeito de seu controle físico-químico. PUBVET, Londrina, V. 6, N. 26, Ed. 213, Art. 1419, 2012.

em dessecador até a temperatura ambiente e pesar. Repetir as operações de aquecimento e resfriamento até obter peso constante.

CÁLCULO: $100 \times \mathrm{N}=$ cinzas por cento $\mathrm{m} / \mathrm{m}$

$P$

$\mathrm{N}=\mathrm{n}^{\circ}$ de gramas de cinzas

$\mathrm{P}=\mathrm{n}^{\circ}$ de gramas da amostra

2.6.1.3 Cinzas Insolúveis em ácido clorídrico a 10\% (BRASIL, 2005a)

A determinação de cinzas insolúveis em ácido clorídrico a $10 \%$ dá uma avaliação de sílica (areia) ou terra existente na amostra.

PROCEDIMENTO: Após a obtenção do resíduo por incineração (cinzas), cuja metodologia encontra-se descrita no item 2.6.1.2, deve-se adicionar a estas, $20 \mathrm{~mL}$ de ácido clorídrico a $10 \%$ e agitar com bastão de vidro. Posteriormente, filtrar em papel de filtro e lavar a cápsula e o filtro com água quente até não dar mais reação ácida. Transferir o papel de filtro contendo o resíduo para a mesma cápsula em que foi feita a incineração e secar em estufa a $105^{\circ} \mathrm{C}$ por uma hora. Carbonizar em papel cuidadosamente, incinerar em mufla a $550^{\circ} \mathrm{C}$. Resfriar em dessecador até a temperatura ambiente, pesar e repetir as operações de aquecimento e resfriamento até peso constante.

\section{CÁLCULO:}

$\underline{100 \times \mathrm{N}}=$ cinzas insolúveis em ácido clorídrico a $10 \%$, por cento $\mathrm{m} / \mathrm{m}$ $P$

$\mathrm{N}=\mathrm{n}^{\circ}$ de $\mathrm{g}$ de cinzas insolúveis em ácido clorídrico a $10 \%$

$\mathrm{P}=\mathrm{n}^{\circ}$ de g da amostra 
CARRIJO, K.F. et al. Condimentos e especiarias empregados no processamento de alimentos: considerações a respeito de seu controle físico-químico. PUBVET, Londrina, V. 6, N. 26, Ed. 213, Art. 1419, 2012.

2.6.1.4 Lipídeos ou extrato etéreo - Extração direta de Soxhlet (BRASIL, 2005a)

Os lipídeos são substâncias insolúveis em água e solúveis em solventes orgânicos, tais como éter, clorofórmio e acetona, dentre outros e, portanto sua determinação é feita na maioria dos casos pela extração com solventes, sendo bastante utilizado o éter. Quase sempre se torna mais simples fazer uma extração contínua em aparelho do tipo Soxhlet, seguida da remoção por evaporação ou destilação do solvente empregado. O resíduo obtido não é constituído unicamente por lipídeos, mas por todos os compostos que, nas condições da determinação, possam ser extraídos pelo solvente. Estes compostos incluem os ácidos graxos livres, ésteres de ácidos graxos, as lecitinas, as ceras, os carotenóides, a clorofila e outro pigmentos, além dos esteróis, fosfatídeos, vitaminas A e D, óleos essenciais, etc., mas em quantidades relativamente pequenas, que não chegam a representar uma diferença significativa na determinação. Nos produtos em que estas concentrações se tornam maiores, a determinação terá a denominação mais adequada de extrato etéreo (BRASIL, 2005a).

O método de extração etérea é de grande valor na determinação de óleos não voláteis ou fixos, em especiarias como a semente de aipo, a mostarda e as pimentas. No entanto, não é adequado para a determinação de extrato etéreo em especiarias ricas em óleos voláteis, como o cravo-da-índia, o maciz e a noz-moscada, em função das altas temperaturas alcançadas (HART e FISHER, 1971). Em geral, para a determinação dos óleos voláteis das especiarias é preferível um método de destilação por arraste à vapor, que será abordada no item 2.6.1.5, referente à determinação de óleos essenciais.

PROCEDIMENTO: Pesar 2 a 5 gramas da amostra em cartucho de Soxhlet ou em papel de filtro e amarrar com fio de lã previamente desengordurado. No caso de amostras líquidas, pipete o volume desejado, esgote em uma porção de algodão sobre um papel de filtro duplo e coloque para secar em uma estufa 
CARRIJO, K.F. et al. Condimentos e especiarias empregados no processamento de alimentos: considerações a respeito de seu controle físico-químico. PUBVET, Londrina, V. 6, N. 26, Ed. 213, Art. 1419, 2012.

a $105^{\circ} \mathrm{C}$ por uma hora. Transferir o cartucho ou papel de filtro amarrado para o aparelho extrator do tipo Soxhlet. Acople o extrator ao balão de fundo chato, previamente tarado a $105^{\circ} \mathrm{C}$. Adicione éter em quantidade suficiente para um Soxhlet e meio. Adapte a um refrigerador de bolas. Mantenha, sob aquecimento em chapa elétrica, à extração contínua por 8 (quatro a cinco gotas por segundo) ou 16 horas (duas a três gotas por segundo). Retire o cartucho ou papel de filtro amarrado, destile o éter e transfira o balão com o resíduo extraído para uma estufa a $105^{\circ} \mathrm{C}$, mantendo por cerca de 1 hora. Resfrie em dessecador até a temperatura ambiente. Pese e repita as operações de aquecimento por 30 minutos em estufa e resfriamento até peso constante (no máximo 2 horas).

CÁLCULO: $\underline{100 \times \mathrm{N}}=$ extrato etéreo por cento $\mathrm{m} / \mathrm{m}$

$$
P
$$

$\mathrm{N}=\mathrm{n}^{\circ}$ de gramas de lipídio

$\mathrm{P}=\mathrm{n}^{\circ}$ de gramas da amostra

NOTA: no caso de produtos contendo alta proporção de carboidratos, deve-se pesar a amostra sob papel de filtro e lave com cinco porções de $20 \mathrm{~mL}$ de água. Coloque em estufa a $105^{\circ} \mathrm{C}$ por uma hora para secagem e proceda a extração conforme acima descrito.

\subsubsection{Determinação de óleos essenciais (BRASIL, 2005a)}

Óleos essenciais são misturas complexas compostas por hidrocarbonetos de natureza terpênica e suas formas oxidadas, principalmente mono e sesquiterpenos e fenilalcanos, essencialmente, os fenilpropanos. São voláteis, odoríferos, imiscíveis ou muito pouco miscíveis com água, sendo arrastados pelo vapor d'àgua. São muito comuns em algumas famílias como por exemplo: Lebiatae - hortelã, sálvia e alecrim; Umbelliferae - erva-doce, funcho, anis; Lauraceae - canela; Zingeberaceae - gengibre; Myrtaceae - cravo-da-Índia, 
CARRIJO, K.F. et al. Condimentos e especiarias empregados no processamento de alimentos: considerações a respeito de seu controle físico-químico. PUBVET, Londrina, V. 6, N. 26, Ed. 213, Art. 1419, 2012.

entre outras. São produzidos nos diferentes órgãos vegetais, estando contidos em estruturas especiais ou conjuntos celulares denominados aparelhos secretores (BRASIL, 2005a).

A determinação quantitativa do teor de óleos essenciais em condimentos vegetais faz-se regularmente em laboratório, pela execução de um procedimento simples de hidrodestilação (arraste à vapor) do vegetal, utilizando-se aparelhos de vidro, como o aparelho de Clevenger modificado (ibid), acoplado a um condensador bola, conforme as figuras a seguir.

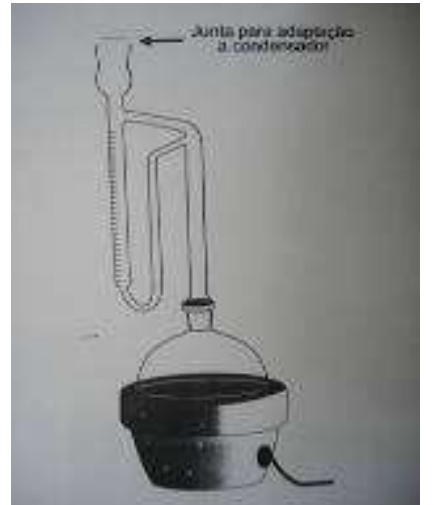

Figura 1. Aparelho de Clevenger Modificado FONTE: BRASIL (2005a)

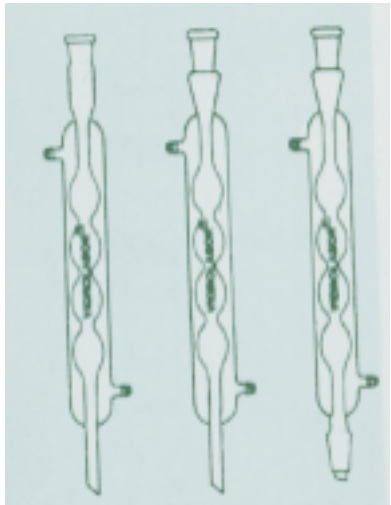

Figura 2. Condensador bola Fonte: http://images.com.br (2008)

PROCEDIMENTO: Pesar 100 gramas da amostra e transferir, com o auxílio de um funil, para um balão de vidro de fundo redondo; tornando-se conveniente que a quantidade de amostra não exceda $1 / 3$ do volume do balão. Adicionar água quente (cerca de metade do volume do balão) e acople ao aparelho de Clevenger. Preencher com água a parte graduada do referido aparelho antes de iniciar a destilação. Aqueça e mantenha em ebulição por no mínimo 4 horas ou destile até que duas leituras consecutivas em intervalo de 1 hora não mostrem alteração no volume de óleo obtido. Esfrie e leia o volume destilado diretamente na parte graduada do tubo de Clevenger. Forma-se inicialmente uma emulsão que com o passar das horas se separa. 
CARRIJO, K.F. et al. Condimentos e especiarias empregados no processamento de alimentos: considerações a respeito de seu controle físico-químico. PUBVET, Londrina, V. 6, N. 26, Ed. 213, Art. 1419, 2012.

CÁLCULO: $100 \times \mathrm{n}=$ teor de óleos essenciais

$\mathrm{P}$

$\mathrm{n}=\mathrm{n}^{\circ}$ de $\mathrm{mL}$ de óleo essencial destilado

$\mathrm{P}=$ massa em $\mathrm{g}$ da amostra de condimento vegetal.

2.6.1.6 Extrato Alcoólico (BRASIL, 2005a)

É um tipo de extração em que o solvente empregado é o álcool. O resíduo obtido é chamado de extrato alcoólico o qual, nos produtos ricos em óleos voláteis, essências, etc., representa um dado precioso na avaliação destes últimos. Como toda extração com solventes, ela poderá ser feita diretamente por simples percolação ou em aparelhos de extração contínua.

PROCEDIMENTO: Pesar 2 gramas da amostra em um béquer de $50 \mathrm{~mL}$. Transferir para um balão volumétrico de $100 \mathrm{~mL}$, com auxilio de $80 \mathrm{~mL}$ de álcool. Agitar em intervalos de 30 minutos, por 4 horas. Deixe de repouso por 16 horas. Complete o volume com álcool. Filtrar em papel filtro seco. Receber o filtrado em um frasco Erlenmeyer. Transferir com o auxílio de uma pipeta, 50 $\mathrm{mL}$ do filtrado para um béquer de $100 \mathrm{~mL}$, previamente tarado. Coloque $\mathrm{o}$ béquer em banho-maria até completa evaporação do solvente. Aqueça a estufa a $105^{\circ} \mathrm{C}$ por 1 hora, resfriar em dessecador à temperatura ambiente e pesar. Repetir a operação até obter o peso constante.

CÁLCULO: $100 \times \mathrm{N}=$ extrato alcoólico, por cento $\mathrm{m} / \mathrm{m}$

$P$

$\mathrm{P}=\mathrm{n}^{\circ}$ de $\mathrm{g}$ de amostra contida na alíquota usada para a secagem

$\mathrm{N}=\mathrm{n}^{\circ}$ de $\mathrm{g}$ de extrato fixo a $105^{\circ} \mathrm{C}$.

\subsubsection{Métodos de Análise de Condimentos preparados}

$\mathrm{Na}$ categoria condimentos preparados, incluem-se vários produtos obtidos pela simples mistura de condimentos naturais ou elaborados, com ou sem a adição de outras substâncias alimentícias e apresentadas sob a forma de pós, pastas, molhos, em emulsão ou suspensão. São exemplos: catchup, 
CARRIJO, K.F. et al. Condimentos e especiarias empregados no processamento de alimentos: considerações a respeito de seu controle físico-químico. PUBVET, Londrina, V. 6, N. 26, Ed. 213, Art. 1419, 2012.

mostarda preparada, maionese, molho inglês, molho shoyu, temperos prontos à base de alho e sal, entre outros. A análise destes produtos inclui, entre outras: as determinações de substâncias voláteis, glicídios redutores em glicose, glicídios não-redutores em sacarose, amido, cinzas, extrato etéreo, cloretos em cloreto de sódio, corantes artificiais e acidez, dependendo da composição do produto. No caso de condimentos com alto teor de cloreto de sódio, o extrato etéreo deverá ser efetuado com éter anidro.

Tanto para condimentos simples como para os preparados, as determinações de substâncias voláteis, cinzas, lipídeos, protídeos, fibra alimentar, carboidratos por diferença e sódio são relevantes para fins de informação nutricional. Nesse sentido, a determinação de gorduras saturadas se faz no caso de condimentos preparados contendo óleo ou gordura na sua composição, bem como acidez, para cálculo de valor calórico, principalmente quando o condimento preparado contiver vinagre.

A seguir, será abordada a metodologia para determinação de isotiocianato de alila em mostarda preparada, cuja prova é bastante específica.

2.6.2.1 Determinação de isotiocianato de alila em mostarda preparada (BRASIL, 2005a)

No caso da análise de mostarda preparada, além das determinações usuais citadas para condimentos preparados, faz-se também a determinação de isotiocianato de alila. Este é um composto responsável pelo odor e sabor pungente da mostarda, é o principal componente, em porcentagem, do óleo essencial desta especiaria.

\section{PROCEDIMENTO:}

De acordo com as normas do Instituto Adolfo Lutz (BRASIL, 2005a) a técnica consiste na pesagem de 5 gramas de amostra e posteriormente adição de $100 \mathrm{~mL}$ de água, que deverá ficar em contato em frasco fechado, durante 2 horas a $37^{\circ} \mathrm{C}$. Em seguida procede-se a destilação da mistura, recebendo o 
CARRIJO, K.F. et al. Condimentos e especiarias empregados no processamento de alimentos: considerações a respeito de seu controle físico-químico. PUBVET, Londrina, V. 6, N. 26, Ed. 213, Art. 1419, 2012.

destilado em $5 \mathrm{~mL}$ de solução de hidróxido de sódio a $10 \%$, usando um adaptador que mergulhe na solução amoniacal. Completada a destilação, adiciona-se $25 \mathrm{~mL}$ de solução de nitrato de prata 0,1M e em seguida o frasco deve ser aquecido em banho de água de $80-85^{\circ} \mathrm{C}$, durante 30 minutos, com agitação freqüente e posteriormente esfriado. Completar o volume a $100 \mathrm{~mL}$ e filtrar. Medir $50 \mathrm{~mL}$ do filtrado e adicionar $4 \mathrm{~mL}$ de ácido nítrico e em seguida titular com solução de tiocianato de amônio $0,1 \mathrm{M}$, usando como indicador algumas gotas de solução de sulfato de ferro III.

CÁLCULO: $25 \times 2 \mathrm{~V} \times 0,00495 \times 100=$ isotiocianato de alila por cento $\mathrm{m} / \mathrm{m}$ $P$

$V=n^{\circ}$ de $m L$ gasto da solução de tiocianato de amônio $0,1 M$.

$\mathrm{P}=\mathrm{n}^{\circ}$ de $\mathrm{g}$ da amostra

\section{CONCLUSÃO}

O uso de condimentos e especiarias tanto em nível industrial quanto doméstico, apresenta muitos benefícios, mas também muitos riscos, sobretudo em função da adição de outros materiais e/ou substâncias que não fazem parte da composição do condimento (simples ou preparado). Desta forma, tanto a análise microbiológica quanto a análise físico-química são de fundamental importância na verificação da qualidade destes produtos. Dentre os métodos físico-químicos para avaliação tanto de condimentos simples quanto preparados, a determinação de cinzas (resíduo mineral fixo), cinzas insolúveis em ácido clorídrico a $10 \%$ e extrato alcoólico, são os mais utilizados, devendo seus resultados serem comparados com os valores estabelecidos pela legislação, para a verificação de adulterações. 


\section{REFERÊNCIAS BIBLIOGRÁFICAS}

ALMEIDA, A.P.G. Avaliação da Influência do processo de irradiação em especiarias utilizando a técnica de difração dos raios-x. Dissertação de Mestrado. Universidade Federal do Rio de Janeiro, set. 2006, 102p.

ARIMA, H.K.; NETO, M.P. Ação dos aditivos e ingredientes. In: Curso sobre a qualidade e Processamento de presunto cozido e apresuntado. Instituto de Tecnologia de Alimentos. Centro de Tecnologia de Carnes. Campinas.1995. 103p.

BEDIN, C.; GUTKOSKI, S.; WIEST, A.C. Atividade antimicrobiana das especiarias. Revista Higiene Alimentar, vol.13, n.65, São Paulo, Out.1999, p.26-29.

BRASIL. Ministério da Agricultura, Pecuária e Abastecimento. Departamento de Inspeção de Produtos de Origem Animal (DIPOA). Decreto Lei no 30.691, de 29 de março de 1.952. Alterado pelos Decretos no 1.255 de 25/06/62, no 1.236 de 02/09/94, no 1.812 de 08/02/96, no 2.244 de 04/06/97 e. no 6385, de 27/02/2008 Regulamento da Inspeção Industrial e Sanitária de Produtos de Origem Animal (RIISPOA). Brasília: RIISPOA, 2008.

- Ministério da Saúde. Agência Nacional de Vigilância Sanitária. Resolução da Comissão Nacional de Normas e Padrões para Alimentos no 12, de 24 de julho de 1978. Aprova as normas técnicas especiais relativas a alimentos (e bebidas) para efeito em todo território nacional.

Ministério da Saúde. Agência Nacional de Vigilância Sanitária. Instituto Adolfo Lutz. Métodos de Análise Microscópica de alimentos: isolamento de elementos histológicos, vol. 1., Brasília, 1999.

. Ministério da Saúde. Agência Nacional de Vigilância Sanitária. Resolução RDC no 1, de 02 de janeiro de 2001. Aprova o regulamento técnico que aprova o uso de aditivos com a função de realçadores de sabor, estabelecendo seus limites máximos para alimentos.

- Ministério da Saúde. Agência Nacional de Vigilância Sanitária. Resolução RDC no $\overline{175, \text { de }} 08$ de julho de 2003 . Aprova o regulamento técnico de avaliação de matérias macroscópicas e microscópicas prejudiciais à saúde humana em alimentos embalados.

. Ministério da Saúde. Agência Nacional de Vigilância Sanitária. Instituto Adolfo Lutz. Métodos Físico-Químicos para análise de alimentos, 4 ed., Brasília, 2005a.

. Ministério da Saúde. Agência Nacional de Vigilância Sanitária. Resolução RDC no $\overline{276}$, de 22 de setembro de 2005b. Aprova o regulamento técnico para especiarias, temperos e molhos.

CHESCA, A.C.; MOREIRA, P.A.; ANDRADE, S.C.B.J.; D'ANGELIS, C.E.; SILVEIRA, M. Especiarias contaminadas: risco à saúde do consumidor. Revista Higiene Alimentar, vol. 18, n.118, São Paulo, mar. 2004.

EGAN, H.; KIRK, R.S.; SAWYER, R. Analisis quimico de alimentos de Person. Compañía Editorial Continental, S.A, México, 1987.

FROEHLICH, A. GIOMBELLI, A. Ocorrência de bactérias aeróbias mesófilas e de Bacillus cereus em pimenta do reino. Revista Higiene Alimentar, v.16, n.97, São Paulo, jun 2002, p.66-69. 
GERHARDT, U. Especias y condimentos. Tradução por Carlos B. de Quiróz. Zaragoza, España: Ed. Acribia, 1975. 154p.

GERMANO, P.M.L.; GERMANO, M.I.S. Importância e riscos das especiarias. Revista Higiene Alimentar, v.12, n.57, São Paulo, set-out 1998, 23-31p.

HART, F.L; FISHER, H.J. Análisis moderno de los alimentos. Zaragosa: Ed. Acribia, 1971. 619 P.

HEAT, H.B. Sources book of flavours. AVI Publishing Company, Inc., Westport (Connecticut), USA, 1982.

ICMSF.INTERNATIONAL COMMISSION ON MICROBIOLOGICAL SPECIFICATION FOR FOODS (ICMSF). Ecologia microbiana de los alimentos, Zaragoza: Acribia, v.2, p.613-651, 1985.

MADHAVI, D.L.; DESHPANDE, S.S.; SALUN, K.L. Food antioxidants: technological, toxicological and heath perspectives. New York: Marcel Dekker, 1996. 490p.

McKEE, L.H. Microbial contamination of spices and herbs: a review. Lebensmittlel-Wissenschaft und - Technologie, v.28, p. 1-11, 1995.

OLIVEIRA, K.A.M., et al. O alho como agente antimicrobiano na produção avícola. Revista Nacional da Carne, v.315, mai.2003.

OLIVEIRA, L.A.; FRANCO, R.M.; CARVALHO, J.C.A.P. Enterobacteriaceae em especiarias utilizadas na elaboração de embutidos cárneos. Revista Higiene Alimentar, vol. 06, n.22, São Paulo, jul. 1992, p.27-33.

PARDI, M. C. et al. Ciência, Higiene e Tecnologia da Carne. 2a ed.rev. Goiânia: Editora UFG, 1996. v. 2

PARRY, J.W. The story of spices. Chemical Publishing Co. Inc., New York, 1953.

PRZYBYLA, A.E. America's passion for spices. Food Engeenering, vol. 58, p.70-77, 1986.

SOUZA, E.L.; STAMFORD, T.L.M.; LIMA, E.O.; FILHO, J.M.B.; Orégano (Origanum vulgare): uma especiaria como potencial fonte de compostos antimicrobianos. Revista Higiene Alimentar, vol. 19, n.132, São Paulo, jun. 2005, p.40-44. 